\title{
Outcome of Multi-Cystic Dysplastic Kidneys in Children
}

\author{
Suleiman D. Mashat, ${ }^{1}$ Sherif M. El-Desoky, and Jameela Abdulaziz Kari, ${ }^{1, *}$ \\ ${ }^{1}$ Department of Pediatrics, King Abdulaziz University, Jeddah, Kingdom of Saudi Arabia \\ ${ }^{*}$ Corresponding author: Jameela Abdulaziz Kari, Department of Pediatrics, King Abdulaziz University Hospital, P. O. Box: 80215, Jeddah, Kingdom of Saudi Arabia. Tel: +996-5056779048, \\ Fax:+996-126408339, E-mail: jkari@doctors.org.uk \\ Received: June 16, 2015; Accepted: August 2, 2015
}

\begin{abstract}
Background: Renal cystic diseases are important causes of chronic kidney disease (CKD).
Objectives: We report the pattern of renal cystic disease in children and evaluate the outcome of children with multicystic dysplastic kidney (MCDK).

Patients and Methods: Retrospective study of all children with cystic kidney diseases at King Abdulaziz University hospital from 2006 to 2014.

Results: Total of 55 children (30 males); 25 MCDK, 22 polycystic kidney diseases(PKD), 4 nephronophthises and 4 renal cysts. Consanguinity was positive in $96.2 \%$. MCDK and simple renal cyst patients had good renal function while PKD and nephronophthisis developed renal impairment. Most MCKD were diagnosed ante-natally, 16 of them were followed up for 3.4 (1.97) year. Their last creatinine was 33.9 (13.5) umol/L. MCDK was spontaneously involuted at mean age of 2.6 (1.3) years in 56\%.

Conclusions: MCDK is the commonest cystic renal disease and diagnosed ante-natally in the majority of cases. It has a good prognosis.
\end{abstract}

Keywords: Cystic Kidney Disease; Children; Multicystic Dysplastic Kidneys

\section{Background}

Renal cystic diseases are an important cause of chronic kidney disease (CKD). They have been classified in various ways, but from a clinical perspective it is perhaps most useful to separate them into genetic such as (autosomal dominant polycystic kidney disease and autosomal recessive polycystic kidney disease) and non-genetic disorders such as multicystic dysplasia (MCDK) since this approach guides evaluation and management (1).

It is estimated that $70 \%$ of cases of kidney disease in childhood are congenital with possibility of genetic basis (2). In the kingdom of Saudi Arabia (KSA) due to the high rate of consanguineous marriages, this percentage is preassembly even higher particularly for disease with an autosomal recessive transmission (3, 4). There are few published epidemiological studies on the actual incidence of various genetically transmitted diseases in KSA. Mattoo et al. reported two decades back that children in KSA probably have higher incidence of polycystic kidney disease (5).

Unilateral multicystic dysplastic kidney (MCDK) is one of the commonest abnormalities detected by antenatal ultrasound (6) and the second most frequent cause of a palpable abdominal mass in infants (7). Al-Ghwery et al. reported 35 cases from the Kingdom of Saudi Arabia (KSA) with good prognosis on conservative management (8).

\section{Objectives}

In this study we report the pattern renal cystic disease in children referred to a tertiary teaching hospital. We also look at the outcome of MCDK.

\section{Patients and Methods}

We have retrospectively reviewed our database of Pediatric nephrology unit at King Abdulaziz University Hospital (KAUH) between 2006 and 2014. We have included all children with cystic kidney diseases. We evaluated children with MCDK with follow up duration more than 6 months as a separate group. We reviewed their medical and electronic files.

We recorded epidemiological data, history of consanguinity and data of height, blood pressure, creatinine at presentation and on the last follow up. We have calculated estimated glomerular filtration rate (e-GFR) using Schwartz formula (9). Hypertension was defined as blood pressure (BP) above 95 centile for age, height and sex.

At presentation and on the last follow up, we have staged CKD into stage 1 to 5 , according to calculated e-GFR (10). We recorded the need for renal replacement therapy (RRT), its modalities and duration. The results were expressed as mean \pm standard deviation (SD).

Copyright (C) 2015, Growth \& Development Research Center. This is an open-access article distributed under the terms of the Creative Commons Attribution-NonCommercial 4.0 International License (http://creativecommons.org/licenses/by-nc/4.0/) which permits copy and redistribute the material just in noncommercial usages, provided the original work is properly cited. 
Ethical approval was obtained for this study from the local ethical approval committee of Faculty of Medicine at King Abdulaziz University.

\section{Results}

Fifty five children (30 males) were diagnosed as cases of renal cystic diseases. Seventeen (30.1\%) stopped following in less than 6 months. Nine (52.9\%) of subjects were Saudis and eight (47.1\%) were non-Saudis. The Mean (SD) age at presentation to our hospital was 2.3 (3.6) years. The mean (SD) age at the last follow up was 5.7 (4.97) year. History of consanguinity between parents was positive in 25 (96.2\%) children, negative in one child and unknown in 29 patients. Following the initial ultrasound (US) studies, children were classified into 25 children as multicystic dysplastic kidney disease (MCDK), 22 as polycystic kidney disease (PKD), 4 as nephronophthisis and 4 as renal cyst (Table 1 ).

On the last follow up of 38 children who had more than 6 months follow up; 4 children had died and 34 had different stages of CKD; 16 children had stage I, 7 children stage II, 6 children stage III, 2 children stage IV, and 7 children were in stage V CKD. Four children received renal replacement therapy ( 2 hemodialysis and 2 renal transplantation) (Table 2). Seventeen (30.1\%) children were lost to follow up before 6 months; 9 (52.9\%) were Saudis and 8
(47.1\%) were from other nationalities.

When we analyzed MCDK as a separate group, 11 children had nuclear study (DMSA: dimercaptosuccinic acid scan) which confirmed the diagnosis. 9 children had less than 6 months follow up duration (7 were lost to follow up) and therefore were excluded. On last follow up 9 out of 16 children, had involutes of their kidneys as shown by the US, at mean age of 2.6 (1.3) years.

At initial presentation, MCKD was the commonest type of pediatric cystic kidney disease occurring in KAUH accounting for $45.5 \%$ of the cases with male to female ratio of 3:1. However, only 16 cases had follow up of 6 months. Their Mean (SD) age at presentation was 0.92 (2.2) years. Mean (SD) of their initial serum creatinine (SD) was 53 (27) umol/L. Initial urine analysis showed negative proteinuria in $93.8 \%$ of the cases and trace proteins in one (6.2\%) child. Also, initial blood pressure was measured and was normal in $93.8 \%$ of the cases and only one case was hypertensive. All children except one were diagnosed antenatally.

Table 2 gives a summary of children with MCKD. Patients were followed up for the duration of 3.4 (1.97) years. Last creatinine was 33.9 (13.5) $\mu \mathrm{mol} / \mathrm{L}$. Twenty five percent were in stage I CKD and did not progress while the other $75 \%$ of the cases had regressed to stage I CKD (75\%) and stage II CKD (25\%).

Table 1. Summary of Clinical Data of Different Categories at Presentation After Excluding Those With Less Than 6 Months Follow Up

\begin{tabular}{|c|c|c|c|c|c|c|}
\hline Diagnosis & $\begin{array}{l}\text { Number } \\
\text { (Males) }\end{array}$ & $\begin{array}{l}\text { Mean Age (SD) at } \\
\text { Presentation, } y\end{array}$ & $\begin{array}{l}\text { Mean Initial Creati- } \\
\text { nine(SD), } \mu \mathrm{mol} / \mathrm{L}\end{array}$ & $\begin{array}{c}\text { Mean Initial GFR(SD), } \\
\mathrm{mL} / \mathrm{min} / 1.73 \mathrm{~m}^{2}\end{array}$ & $\begin{array}{l}\text { Protein-Uria (Dip- } \\
\text { stick Analysis) }\end{array}$ & Hypertension, \% \\
\hline MCDK & $16(12)$ & $0.92(2.2)$ & $53(27)$ & $57.4(35.2)$ & Negative $=15$, Trace $=1$ & $1(6.25)$ \\
\hline PKD & $17(7)$ & $2.4(3.2)$ & $194.4(296.3)$ & $35.7(27.3)$ & $\begin{array}{c}\text { Negative }=12, \text { Trace }= \\
2,+1=2,+2=1\end{array}$ & $15(88.2)$ \\
\hline Nephrono-phthisis & $3(1)$ & $9.3(3.5)$ & $302.7(354)$ & $42.2(46.8)$ & Negative $=2$, Trace $=1$ & $2(66)$ \\
\hline Renal cyst & $2(1)$ & $8(7.1)$ & $38.5(13.4)$ & $114.6(7.1)$ & Negative $=2$ & $0(0)$ \\
\hline
\end{tabular}

Table 2. Clinical Data of Different Groups at the Last Follow up

\begin{tabular}{|c|c|c|c|c|c|c|}
\hline Diagnosis & $\begin{array}{l}\text { Duration of } \\
\text { Follow up, y }\end{array}$ & $\begin{array}{l}\text { Last Creatinine, } \\
\text { Umol/L }\end{array}$ & $\begin{array}{c}\text { Mean Last GFR(SD), } \\
\mathrm{mL} / \mathrm{min} / \mathrm{M}^{2}\end{array}$ & Stage of CKD & Protein-Uria & RRT \\
\hline MCDK & $3.4(1.97)$ & $33.9(13.5)$ & $103.9(16.3)$ & Stage $1=13$, Stage $2=3$ & Negative $=15$, Trace $=1$ & None $=16$ \\
\hline PKD & $3.2(1.98)$ & $201.4(166.3)$ & $35.1(31.5)$ & $\begin{array}{c}\text { Stage } 1=1, \text { Stage } 2=2, \\
\text { Stage } 3=6, \text { Stage } 4=2, \\
\text { Stage } 5=6\end{array}$ & $\begin{array}{c}\text { Negative }=12, \text { Trace }=2, \\
+1=2,+2=1\end{array}$ & $\begin{array}{c}\text { None }=15, \\
\text { Hemodialysis }=2\end{array}$ \\
\hline $\begin{array}{l}\text { Nephrono- } \\
\text { phthisis }\end{array}$ & $3.7(0.6)$ & $216.7(271.3)$ & $61.3(41.8)$ & Stage $2=2$, Stage $5=1$ & Negative $=1$, Trace $=2$ & $\begin{array}{c}\text { Transplantation }=2, \\
\text { None }=1\end{array}$ \\
\hline Renal cyst & $2.3(1.1)$ & $28(11.3)$ & $146.6(15)$ & Stage $1=2$ & Negative $=2$ & None $=2$ \\
\hline
\end{tabular}




\section{Discussion}

In this retrospective analysis of a single center experience, we observed that MCDK was the commonest renal cystic disease with the majority diagnosed antenatally. This is similar to previous reports $(6,7)$. The estimated incidence of MCKD is approximately 1 in 3640 births (11). More than $90 \%$ of our cohort were diagnosed antenatally which is in line with previous observation that MCDK is usually diagnosed early in life and more often with routine use of prenatal ultrasonography. This also reflects the improvement in antenatal services in the Kingdom of Saudi Arabia (KSA) over the last two decades $(12,13)$.

A considerable number of our children with MCDK were lost to follow up and this could be explained by the possibility of relaxation of the parents after counseling about the good prognosis of this condition. Some reports previously suggested that once the diagnosis of MCDK is made, no urological follow-up is needed. The primary care provider should monitor patients with MCDK for hypertension, abdominal mass and urinary tract infection (14). Recent reports indicate that a substantial proportion of children with single functioning kidney develop renal injury during childhood, at median age of 12.8 years. Therefore, close follow-up of albuminuria, blood pressure and eGFR are warranted to identify chronic kidney disease in its early stages (15). The importance of the long term follow up should be stressed to the parents, despite of good prognosis of MCDK.

In the majority of cases, a unilateral MCDK will completely involute over time (16). We have observed that as $56 \%$ of MCDK cases were involuted at mean age of 2.6 (1.3) years. This is similar to previous reports emphasizing that most MCDK kidneys undergo involution during the first five years of life (16-18). The other study showed that $33 \%$ of the MCDK kidneys had completely involuted at 2 years of age, $47 \%$ at 5 years, and $59 \%$ at 10 years (19). There is usually compensatory hypertrophy of the contralateral kidney which maintains normal kidney function (17). Al-Ghwery et al. from the central province of KSA reported that $86 \%$ of children with MCDK had a complete or partial involution of the affected kidneys at mean age of 43.6 months (8).

Hypertension is very rare in children with MCDK and a recent systematic review of 29 studies revealed that only six cases in 1115 eligible patients were hypertensive (20). Resolution of hypertension is usually achieved by nephrectomy (21), but hypertension may persist even after removal of MCDK (22). Hypertension could be rennin mediated (23) and can be transient in infants where there are difficulties in measurement of $\mathrm{BP}(24,25)$. It is still uncertain how often and for how long children with a unilateral MCDK need to be assessed for hypertension. We measured the blood pressure at the initial presentation and regularly after that. On the last follow up, the majority were normotensive with only one case with high BP readings.

Children with MCKD are increasingly managed con- servatively and are followed up throughout childhood because they are perceived to be at increased risk of developing Wilms' tumor. This risk is still poorly defined and somewhat controversial. Therefore, the strategy and the duration of follow up do not seem to be based on evidence. The development of a registry for children with MCKD would increase the precision of their risk estimate to develop Wilms' tumor (6).

Isolated unilateral MCDK has good prognosis, bad prognosis is linked to its association with other anomalies as well as to bilateral MCDK when end stage kidney disease will be a risk (26).

The majority of children with PKD in our cohort were hypertensive and their CKD progressed. This is expected and similar to previous reports from other parts of the world (1).

Our study has several limitations which include the retrospective nature of the study, small number of patients and rather short duration of follow up.

\subsection{Conclusion}

MCKD is the commonest renal cystic disease in children and it has good prognosis on conservative management.

\section{References}

1. Rohatgi R. Clinical manifestations of hereditary cystic kidney disease. Front Biosci. 2008;13:4175-97.

2. Bockenhauer D, Medlar AJ, Ashton E, Kleta R, Lench N. Genetic testing in renal disease. Pediatr Nephrol. 2012;27(6):873-83.

3. Kari J. Epidemiology of chronic kidney disease in children. J Nephropathol. 2012;1(3):162-3.

4. Kari JA, Bockenhauer D, Stanescu H, Gari M, Kleta R, Singh AK. Consanguinity in Saudi Arabia: a unique opportunity for pediatric kidney research. Am J Kidney Dis. 2014;63(2):304-10.

5. Mattoo TK, Khatani Y, Ashraf B. Autosomal recessive polycystic kidney disease in 15 Arab children. Pediatr Nephrol. 1994;8(1):85-7.

6. Al Naimi A, Baumuller JE, Spahn S, Bahlmann F. Prenatal diagnosis of multicystic dysplastic kidney disease in the second trimester screening. Prenat Diagn. 2013;33(8):726-31.

7. Farmer DL. Urinary tract masses. Semin Pediatr Surg. 2000;9(3):109-14.

8. Al-Ghwery S, Al-Asmari A. Multicystic dysplastic kidney: conservative management and follow-up. Ren Fail. 2005;27(2):189-92.

9. Schwartz GJ, Work DF. Measurement and estimation of GFR in children and adolescents. Clin J Am Soc Nephrol. 2009;4(11):1832-43.

10. Levey AS, Eckardt KU, Tsukamoto Y, Levin A, Coresh J, Rossert J, et al. Definition and classification of chronic kidney disease: a position statement from Kidney Disease: Improving Global Outcomes (KDIGO). Kidney Int. 2005;67(6):2089-100.

11. James $\mathrm{CA}$, Watson AR, Twining P, Rance $\mathrm{CH}$. Antenatally detected urinary tract abnormalities: changing incidence and management. Eur JPediatr. 1998;157(6):508-11.

12. Raboei E, Abou-Seoud M, Abou-Nassef N, Mehboob F, Saggaf A, Luoma R. Prenatal ultrasound screening of the urinary tract is useful. Pediatr Surg Int. 2002;18(5-6):432-4

13. Neel KF, El-Faqih SR, De Castro R, Abu Daia JM, Al-Shammari AM, Al-Jasser A, et al. Presentation of Posterior Urethral Valves in Saudi Arabia in the 90's. Saudi J Kidney Dis Transpl. 2001;12(4):516-9.

14. Onal B, Kogan BA. Natural history of patients with multicystic dysplastic kidney-what followup is needed? J Urol. 2006;176(4 Pt 1):1607-11.

15. Sukthankar S, Watson AR. Unilateral multicystic dysplastic kidney disease: defining the natural history. Anglia Paediatric Nephrourology Group. Acta Paediatr. 2000;89(7):811-3. 
16. John U, Rudnik-Schoneborn S, Zerres K, Misselwitz J. Kidney growth and renal function in unilateral multicystic dysplastic kidney disease. Pediatr Nephrol. 1998;12(7):567-71.

17. Rottenberg GT, Gordon I, De Bruyn R. The natural history of the multicystic dysplastic kidney in children. Br J Radiol. 1997;70(832):347-50.

18. Aslam M, Watson AR, Trent. Anglia MSG. Unilateral multicystic dysplastic kidney: long term outcomes. Arch Dis Child. 2006;91(10):820-3.

19. Narchi H. Risk of hypertension with multicystic kidney disease: a systematic review. Arch Dis Child. 2005;90(9):921-4.

20. Webb NJ, Lewis MA, Bruce J, Gough DC, Ladusans EJ, Thomson AP, et al. Unilateral multicystic dysplastic kidney: the case for nephrectomy. Arch Dis Child. 1997;76(1):31-4.

21. Snodgrass WT. Hypertension associated with multicystic dys- plastic kidney in children.J Urol. 2000;164(2):472-3.

22. Konda R, Sato H, Ito S, Sakai K, Kimura N, Nagura H. Renin containing cells are present predominantly in scarred areas but not in dysplastic regions in multicystic dysplastic kidney.J Urol. 2001;166(5):1910-4.

23. Oliveira EA, Silva AC, Rabelo EA, Filgueiras FF, Pereira AK, Mesquita FM. Spontaneous improvement of hypertension in multicystic dysplastic kidney: a case report. Pediatr Nephrol. 2002;17(11):954-8.

24. Watson AR. Hypertension and multicystic dysplastic kidney. Pediatr Nephrol. 2003;18(10):1077.

25. Narchi H. Risk of Wilms' tumour with multicystic kidney disease: a systematic review. Arch Dis Child. 2005;90(2):147-9.

26. Kolvek G, Podracka L, Rosenberger J, Stewart RE, van Dijk JP, Reijneveld SA. Solitary functioning kidney in children-a followup study. Kidney Blood Press Res. 2014;39(4):272-8. 